Çukurova Üniversitesi Mühendislik Mimarlık Fakültesi Dergisi, 31(ÖS 1), ss. ÖS 11- ÖS 18, Ağustos 2016 Çukurova University Journal of the Faculty of Engineering and Architecture, 31(ÖS 1), pp. SI 11- SI 18, August 2016

\title{
En Aw 6063 Alüminyum Alaşımı Boruların Plakalara Dıştan Bir Takım Yardımıyla Sürtünme Kaynağı Yapılabilirliğinin İncelenmesi
}

\author{
Cemal MERAN ${ }^{* 1}$, Emre KORKMAZ ${ }^{1}$, Elif AYKANAT ${ }^{1}$, Selin DEĞİRMENCí ${ }^{1}$ \\ ${ }^{1}$ Pamukkale Üniversitesi Mühendislik Fakültesi Makine Mühendisliği Bölümü, 20160, Denizli
}

Geliş tarihi: 23.12.2015 Kabul tarihi: 30.03 .2016

\section{Özet}

Eşanjör ve ekonomizerlerde sıklıkla rastladığımız boru-plaka kaynak bağlantılarında kullanılan geleneksel kaynak yöntemlerine alternatif olabilecek olan bu çalışmada AlMg0,7Si (EN AW 6063) alüminyum alaşımı malzemeden üretilen boruların yine aynı malzemeden üretilen plakalara dışarıdan bir takım yardımıyla sürtünme kaynağı yapılabilirliği incelenmiştir. Çalışma esnasında 5x50x70 mm boyutlarındaki AlMg0,7Si malzemeden plakalara önce Ø20,5, Ø21, Ø21,5, Ø22 mm ölçülerinde delikler açılmıştır. Plakalara $2 \mathrm{~mm}$ et kalınlığında, $20 \mathrm{~mm}$ çapında ve sırasıyla 45,5, 46, 46,5, $47 \mathrm{~mm}$ olmak üzere 4 farklı uzunluktaki borular $950 \mathrm{~min}^{-1}$ devir sayısında dışarıdan bir takım yardımıyla sürtünme kaynağ (DTYSK) ile birleştirilmiştir. Deneyler sırasında takım omzu ve boru arasındaki baskı yükleri sabit tutularak her bir parametre için kaynak esnasında ulaşılan deney sıcaklıkları tespit edilmiştir. Kaynaklı bağlantıların özel olarak hazırlanan fikstür yardımıyla kesme deneyleri yapılmıştır. Kaynaklı bağlantı kesme mukavemetleri deney parametrelerine bağlı olarak tespit edilmiştir.

Anahtar Kelimeler: 6063, AlMgSi, DTYSK, Sürtünme kaynağı, Sürtünme karıştırma kaynağı

\section{Investigation of Friction Weldability of En Aw 6063 Aluminium Alloy Tube to Tube Plate Using an External Tool}

\begin{abstract}
The traditional welding methods are commonly used tube to tube plate of heat exchangers and economiser. In this study it was investigated that application of an alternative welding method which called friction welding of tube to tube plate by using an external tool was used joining of $\mathrm{AlMg} 0,7 \mathrm{Si}$ (EN AW 6063) aluminium alloy. The AlMg0,7Si plates with dimensions 5x50x70 mm were drilled Ø20,5, $\varnothing 21, \varnothing 21,5, \varnothing 22 \mathrm{~mm}$. The four different sizes AlMg0,7Si tubes with dimensions $2 \mathrm{~mm}$ wall thickness, 20 $\mathrm{mm}$ outer diameter, respectively 45,5, 46, 46,5, and $47 \mathrm{~mm}$ length friction welded to plate using an external tool (FWTPET) at constant $900 \mathrm{~min}-1$ tool rotational speed. The vertical force between tool shoulder and tube was constant during the welding, and temperature was measured at every different welding parameters. The shear test was done for determining for welded joints using special fixture. Shear strength of welded joints were determined depend on welding parameters
\end{abstract}

Keywords: 6063, AlMgSi, FWTPET, Friction welding, Friction stir welding

Sorumlu yazar (Corresponding author) : Cemal MERAN, Pamukkale Üniversitesi Mühendislik Fakültesi Makine Mühendisliği Bölümü, Denizli. cmeran@pau.edu.tr 
EN AW 6063 Alüminyum Alaşımı Boruların Plakalara Dıştan Bir Takım Yardımıyla Sürtünme Kaynă̆ı Yapılabilirliğinin Incelenmesi

\section{GíRiş}

Sürtünme karıştırma kaynağı (SKK) günümüzden yaklaşık 15 y1l önce İngiliz Kaynak Enstitüsü'nde (TWI) geliştirilen ve halen üzerinde oldukça fazla araştırma yapılan bir katı hal kaynak yöntemidir. Geleneksel ergitmeli kaynak yöntemleriyle kaynağ1 güç olan özellikle yaşlanma sertleştirmesine tabi tutulmuş alüminyum alaşımlarının kaynağında başarı ile kullanılmaktadır [1]. Bu yöntem k1sa kaynak süresi, minimum yüzey hazırlama ve otomasyon kolaylığı gibi kendine özgü avantajlarından dolayı uygun bir alternatif kaynak olarak günümüzde kullanılmaktadır [2]. $\mathrm{Bu}$ yöntemden bazı alüminyum alaşımlarının yanı sıra bakır alaşımlarının, titan alaşımlarının ve bazı tür çeliklerin birleştirilmesinde yararlanılmaktadır [3]. Birleştirilecek parçalar alın alına arada boşluk kalmayacak şekilde sabitlendikten sonra parça hareketi ile veya takımın dönme ve ilerleme hareketi ile kaynak yapılabilmektedir [4].

Sürtünme karıştırma kaynağında kullanılan omuz ve karıştırıcı uçtan (pim) oluşan tükenmeyen takım, iş parçalarının birleştirme bölgesinden daldırılır ve birleşme çizgisi boyunca dönerek ilerletilir. Takımın iki ana görevi vardır: (a) iş parçasının 1sıtılması, (b) kaynaklı birleștirmenin oluşması için malzeme akışı [5]. Pim, malzemelere temas ettiğinde sürtünme kaynağında ki duruma benzer bir durum oluşarak temas noktasında 1s1 sürtünmenin de etkisi ile artarak malzemenin plastik şekil değişimine sebep olur. $\mathrm{Bu}$ malzemelerin akışına olanak sağlar. Karıştırıcı uçtan omuza kadar olan bölgedeki sürtünme 1sıs1, karıştırıcı çevresi ile malzeme üst yüzeyi ve omuzun temas yüzeyi arasında yumuşamış (hamurlaşma) bir metal oluşturur ve bu malzeme pimin ucundan arkaya doğru karıştırılır. Karıştırılan malzeme, hidrostatik basınç yardımı ile soğuyarak katılaşır ve birleşme sağlanır [3].

Sürtünme kaynağında ise birleştirme ergimeye bağlı olmadan birleştirilecek parçaların ara yüzeylerinde meydana gelir. Sürtünme kaynağı esnasında malzeme ara yüzeyleri düşük yük altında temas haline getirilir ve deformasyon işlemi sağlanır. Daha sonra uygulanan yükler artırılarak kaynaklanacak parçaların ara yüzeyleri boyunca sürtünme 1Sısı oluşumu sağlanır. $\mathrm{Bu}$ aşamadan sonra sürtünme 1S1S1 üretimi sona erer ve kaynaklanacak parçaların ara yüzeylerinin her iki tarafinda 1sınan malzemeye uygulanan gerilme yavaşça artırılır ve kaynaklı birleşme sağlanır. İşlem sonrası birleşme bölgesinde oluşan metal yığılması torna ile alınarak düzensizlik giderilir [6].

Dıştan bir takım yardımıyla sürtünme kaynağ 1 (DTYSK) ise yukarıda açıklanan sürtünme ve sürtünme karıştırma kaynaklarının bir nevi karışımından oluşmaktadır. Bu yöntemde sürtünme karıştırma kaynağına benzer şekilde omuz ve uçtan oluşan bir takım boru yüzeyine farklı baskı yükleri ve devirlerde sürtünerek boruda sürtünme sebepli yumuşama sağlamaktadır. Sürtünme karıştırma kaynağından farklı olarak ise takım ucun yani pin karıştırma işlemi yapmamakta, boru içinde boşta dönmekte ve takıma ya da iş parçasına ilerleme hareketi verilmemektedir (Şekil 1). İşlem öncesi plaka üzerine boru çapından çok az büyüklükte bir delik açılır. Devamında boru plaka yüzeyinden hafif çıkıntı yapacak şekilde elle montajı yapılır.

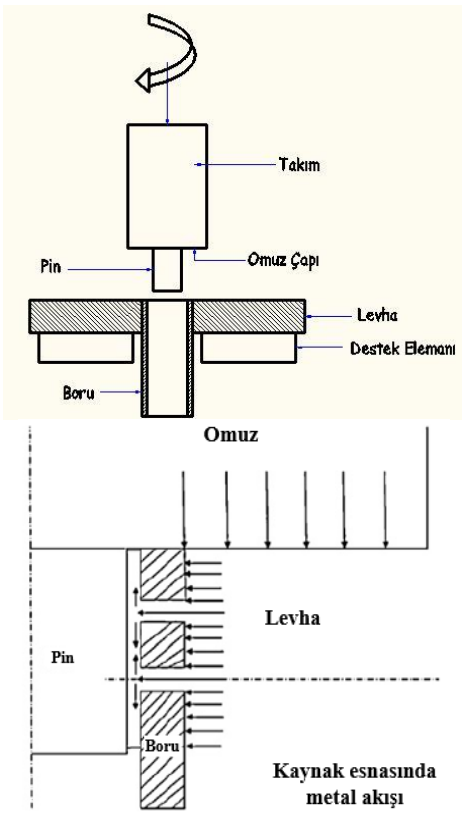

Şekil 1. DTYSK Mekanizması ve kaynak esnasındaki metal akışı [7, 26] 
Devamında boru iç çapından daha küçük çapa sahip uca sahip (sadece yataklama amaçlı) takım boru içine daldırılır ve omuzlardan boru yüzeyine sürtünerek çıkıntı boru kısmını sürtünme 1Sıs1 yardımıyla hamurlaştırır. Hamurlaşan metal takım omzunun aşağı yönlü baskı yüküyle boru ile plaka çapları arasındaki boşluklu kısımdan aşağı doğru akmaya başlar ve kaynak işlemi gerçekleştirilir.

DTYSK'da kaynak kalitesine etki eden parametreler takımın devir sayısı, takımın baskı kuvveti, boru ile takımın arasındaki boşluk, boru uzunluğu (boru ucunun plakadan taşma miktarı), uygulanma süresi, omuz çapı ve sicaklık olarak siralanabilir. $\mathrm{Bu}$ parametreler arasında kaynaklanabilirlik üzerinde en etkili iki parametre takım devir sayısı ve baskı kuvvetidir. $\mathrm{Bu}$ değişkenliklerin her ikisi de kaynak esnasında sürtünme esaslı sıcaklığ 1 doğrudan etkilemekte ve kaynak bölgesinin metalurjik özelliklerinin değişmesine yol açmaktadır. Dıştan bir takım yardımıyla boruların plakalara sürtünme kaynağı üzerine ülkemizde bu bildirinin sahiplerine ait bir adet çalışmadan başka herhangi bir çalışmaya rastlanmamıștır [10]. Uluslararası alanda ise bu çalışmaları ilk defa yapan S. Muthukumaran'a ait çalışmalara rastlanmıştır [11-25].

\section{MALZEME VE YÖNTEM}

Deneyler için kullanılan boru ve plaka malzemesi kimyasal bileşimi Çizelge 1'de, mekanik özellikleri ise Çizelge 2'de verilen EN AW 6063T5 (AlMg0,7Si) alüminyum alaşımıdır. Plaka boruya dıștan bir takım yardımıyla sürtünme kaynağı (DTYSK) yöntemiyle kaynak edilmiştir. DTYSK deneylerinde dik başlı freze, sıcaklık ölçme sistemi, yük ölçer, sürtünme için takım ve deney numunesi bağlama aparatları kullanılmıştır. DTYSK deneylerinde Şekil 2'de görülen dik başlı freze tezgahı ve tutturma tertibatı kullanılmıştır.

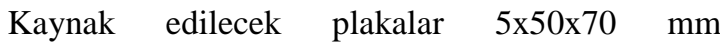
boyutlarında kesilmiştir. Plaka üzerine $\varnothing$ 20,5-22 mm çapında delikler açılmış ve $\varnothing 20 \mathrm{~mm}$ çapında $2 \mathrm{~mm}$ et kalınlığında 4 farklı boyda $(45,5,46,46,5$ ve $47 \mathrm{~mm}$ ) boru, delik içerisine arada $0,25-1 \mathrm{~mm}$ arasında boşluk kalacak şekilde yerleştirilerek kaynak edilmeye çalıșılmıștır (Şekil 3). Borunun plaka ile birleşeceği kısıma yumuşayan metalin akıp doldurmasıyla bağlantısının daha iyi oluşması için boru ucundan $3 \mathrm{~mm}$ aşağıda merkezi olacak şekilde çepe çevre 3 'er mm çapında 8 adet delik açılmıştır. 45,5 $\mathrm{mm}$ boyunda alınan borunun levha yüzeyinden taşma miktarı $0,5 \mathrm{~mm}$ iken $47 \mathrm{~mm}$ boyunda alınan boruda ise bu değer $2 \mathrm{~mm}$ olmaktadır.

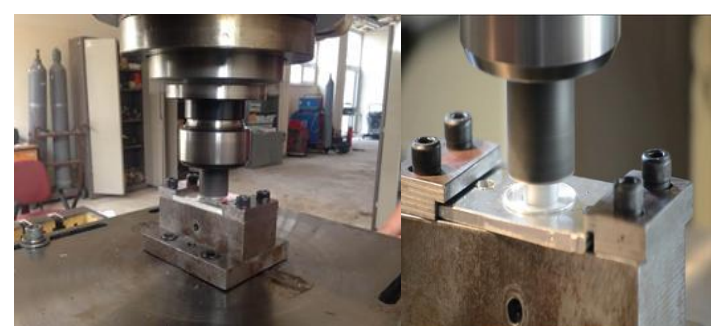

a

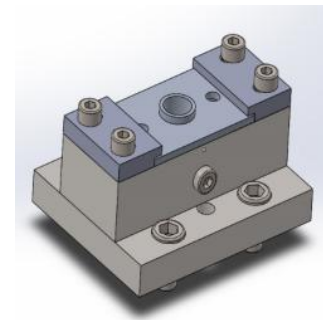

c

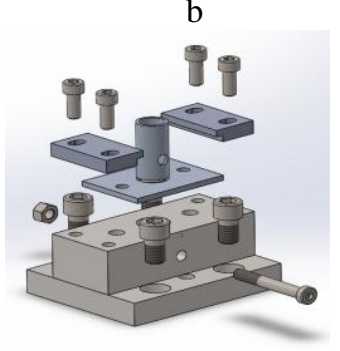

d
Şekil 2. Deney düzeneği; freze (a, b), numune tutturma aparatı (c), numuneleri tutturma tertibatı patlatılmış görünüm (d)

Çizelge 1. EN AW 6063 alüminyum alaşımının kimyasal bileşimi (\%) - EN 573-3 [7]

\begin{tabular}{|c|c|c|c|c|c|c|c|c|c|}
\hline & 的 & $\sum^{\infty}$ & 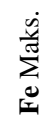 & $\sum_{\dot{j}}^{\frac{\dot{\theta}}{J}}$ & $\sum^{\frac{\dot{n}}{\tilde{J}}}$ & 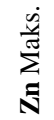 & $\sum$ & $\sum_{\dot{n}}^{\frac{\dot{\theta}}{\mathrm{J}}}$ & 脶 \\
\hline $\begin{array}{l}3 \\
8 \\
8 \\
3 \\
z \\
z\end{array}$ & $\begin{array}{c}0,2 \\
- \\
0,6\end{array}$ & $\begin{array}{c}0,45 \\
- \\
0,90\end{array}$ & 0,35 & 0,10 & 0,10 & 0,10 & 0,1 & 0,10 & $\begin{array}{c}\text { Her biri maks. } \\
\% 0,05 . \\
\text { Toplam maks. } \\
\% 0,15\end{array}$ \\
\hline
\end{tabular}

DTYSK çalışmalarında Şekil 4'de boyutları verilen $\mathrm{X} 210 \mathrm{Cr} 12 \quad(1,2080)$ soğuk iş takım çeliğinden tek bir takım kullanılmıştır. Kaynaklı bağlantıların deney için üretilen özel bir aparat içine yerleştirilerek kesme dayanımları tespit edilmiştir. Yapılan tertibatla kaynaklı bağlantının 
EN AW 6063 Alüminyum Alaşımı Boruların Plakalara Dıştan Bir Takım Yardımıyla Sürtünme Kaynă̆ı Yapılabilirliğinin Incelenmesi

kaynak dikişinden kopması sağlanarak kesme dayanımı değerleri tespit edilmiştir.

Çizelge 2. EN AW 6063 Alüminyum Alaşımının Farklı Temperleme İşlemlerindeki Mekanik Özellikleri - TS EN 7552:2010 [7,8,9]

\begin{tabular}{|c|c|c|c|c|c|c|}
\hline & 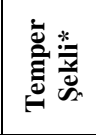 & 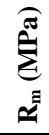 & 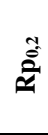 & $\underbrace{8}_{4}$ & 疍 & 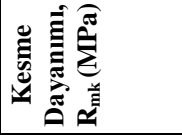 \\
\hline & $\mathrm{O}, \mathrm{H} 111$ & 130 & - & 18 & 25 & \multirow{6}{*}{$\begin{array}{c}0,52 \mathrm{Rm}= \\
0,52 \times 175=90^{[8]} \\
56^{[9]}\end{array}$} \\
\hline \% & $\mathrm{T} 4$ & 130 & 65 & 14 & 50 & \\
\hline 6 & T5 & 175 & 130 & 8 & 65 & \\
\hline 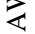 & T6 & 215 & 170 & 10 & 75 & \\
\hline$z$ & T64 & 180 & 120 & 12 & 65 & \\
\hline & T66 & 245 & 200 & 10 & 80 & \\
\hline
\end{tabular}

* Temper șekilleri açıklamalar;

O: Sicak sekillendirme ișlemlerinden sonra gerekli tavlanma özelliklerine ulaşan tavlanmış mamuller $\mathrm{O}$ temper olarak gösterilir.

H111: Germe veya doğrultma gibi daha sonraki işlemler sırasında tavlanmış ve hafifçe gerinme sertleşmesine (H11'den az) uğramış.

T4: Katı çözelti ısıl işlemi görmüş ve doğal yaşlandırılmış.

T5: Yüksek sicaklıktaki bir șekillendirme işleminden soğutulmuş, sonra yapay yaşlandırılmış.

T6: Katı çözelti 1 sıl işlemi görmüş ve yapay yaşlandırılmış

T64: Kat1 çozelti 1sıl işlemi görmüs ve sonra da şekillendirilebilme özelliğini iyileştirmek için eksik yaşlandırma şartlarında (T6 ile T61 arasında) yapay yaşlandırılmıs.

T66: Katı çözelti ısıl işlemi görmüş ve yapay yaşlandırılmış Mekanik özellik seviyesine özel proses kontrolüyle ulașılan T6'dan daha yüksek (6000 serisi alaşımlar).

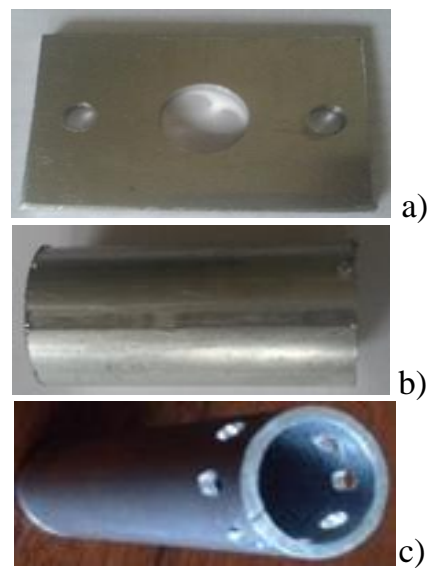

Şekil 3. Deneylerde kullanılan $5 \times 50 \times 70 \mathrm{~mm}$ ebatlarındaki levha (a) ve $\varnothing 20$ çapındaki boru delik açılmadan önce (b) ve sonrası (c)
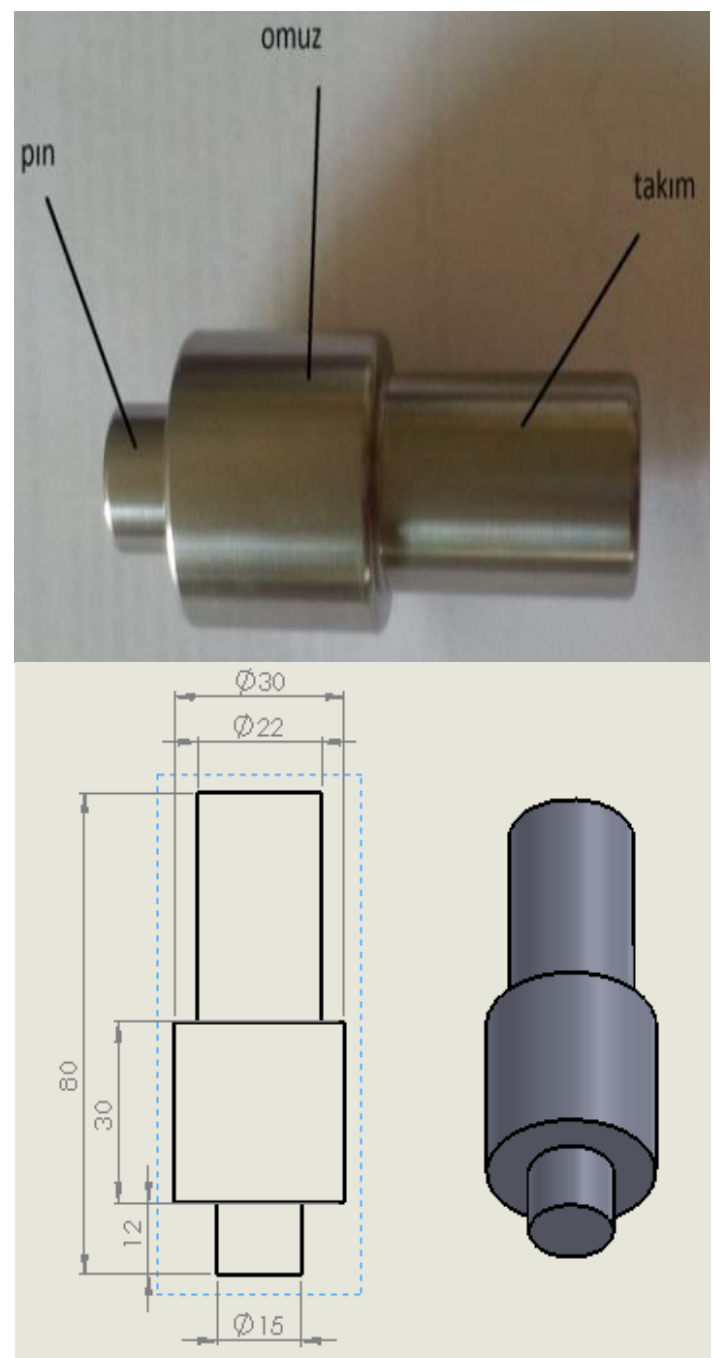

Şekil 4. DTYSK esnasında kullanılan takım

\section{DENEYLER VE SONUÇLAR}

Deneylerde bir boru plakaya DTYSK yöntemiyle birleştirilmiştir. $\mathrm{Bu}$ çalışmada çalışılan deney parametreleri Çizelge 3'de verilmiştir. 16 farkl1 parametrede yapılan deneysel çalışmalar esnasında takım dönme devri $950 \mathrm{~min}^{-1}$ olarak sabit tutulmuştur.

Deneyler esnasında takım omzu tarafindan boruya uygulanan dikey yük 1,4-2,3 $\mathrm{kN}$ arasında ve oluşan sicaklık ise ortalama $410-660{ }^{\circ} \mathrm{C}$ arasında ölçülmüştür. Ölçümler kaynaklanan boru 
yüzeyinin en sıcak olacağı öngörülen bölgeden Testo kızılötesi sıcaklık ölçüm cihazı ile yapılmıştır.

Çizelge 3. Deney parametreleri ve kesme deneyi

\begin{tabular}{|c|c|c|c|c|c|c|c|c|}
\hline \multicolumn{9}{|c|}{ sonuçları } \\
\hline & 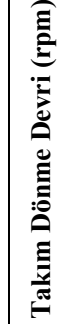 & 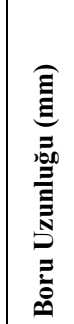 & 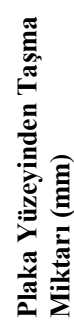 & 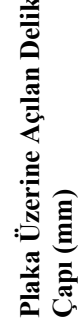 & 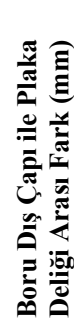 & 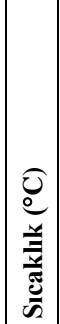 & 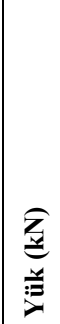 & 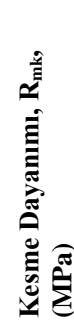 \\
\hline N1 & 950 & 45,5 & 0,5 & 20,5 & 0,25 & 550 & 2,3 & 53 \\
\hline N2 & 950 & 46 & 1 & 20,5 & 0,25 & 500 & 2 & 33 \\
\hline N3 & 950 & 46,5 & 1,5 & 20,5 & 0,25 & 550 & 2 & 40 \\
\hline $\mathrm{N} 4$ & 950 & 47 & 2 & 20,5 & 0,25 & 550 & 2 & 44 \\
\hline N5 & 950 & 45,5 & 0,5 & 21 & 0,5 & 410 & \begin{tabular}{|l|l|}
1,8 \\
\end{tabular} & 22 \\
\hline N6 & 950 & 46 & 1 & 21 & 0,5 & 600 & 2 & 35 \\
\hline N7 & 950 & 46,5 & 1,5 & 21 & 0,5 & 550 & \begin{tabular}{|l|l|}
1,6 \\
\end{tabular} & 10 \\
\hline N8 & 950 & 47 & 2 & 21 & 0,5 & 650 & \begin{tabular}{|l|l|}
1,7 &
\end{tabular} & 2 \\
\hline N9 & 950 & 45,5 & 0,5 & 21,5 & 0,75 & 550 & 1,5 & 36 \\
\hline N10 & 950 & 46 & 1 & \begin{tabular}{|l|}
21,5 \\
\end{tabular} & 0,75 & 500 & $\begin{array}{ll}1,5 \\
\end{array}$ & 5 \\
\hline N11 & 950 & 46,5 & 1,5 & \begin{tabular}{|l|}
21,5 \\
\end{tabular} & 0,75 & 550 & 1,5 & 10 \\
\hline $\mathrm{N} 12$ & 950 & 47 & 2 & \begin{tabular}{|l|}
21,5 \\
\end{tabular} & 0,75 & 650 & 1,7 & 35 \\
\hline $\mathrm{N} 13$ & 950 & \begin{tabular}{|l|}
45,5 \\
\end{tabular} & 0,5 & 22 & 1 & 550 & 1,5 & 4 \\
\hline N14 & 950 & 46 & 1 & 22 & 1 & 600 & 2 & 37 \\
\hline N15 & 950 & 46,5 & 1,5 & 22 & 1 & 660 & \begin{tabular}{|l|l|}
1,4 \\
\end{tabular} & 5 \\
\hline N16 & 950 & 47 & 2 & 22 & 1 & 600 & 2,2 & 17 \\
\hline
\end{tabular}

Her bir kaynak parametresinde 3 adet kaynak yapılmıştır. Bunlardan biri dikey olarak kesilerek, kaynaklı bölge görünür hale getirmek için dağlanmıştır. Şekil 5'de görüleceği üzere bazı kaynak parametrelerinde kaynaklı birleştirmenin gerçekleşmediği makroskobik kesitte net olarak görülmektedir. Bu bağlantıların kesme dayanımları da diğerlerine göre çok düşük çıkmıştır $(\mathrm{N} 7, \mathrm{~N} 8$, N10, N13, N15).

Kaynaklı bağlantıların kesme dayanımlarını ölçmek için özel bir aparat kullanılarak bir pin yardımıyla boru plakadan ayrılmıştır (Şekil 6). Boru plaka ara yüzey kesme dayanımları Çizelge 3'de verilmiştir.

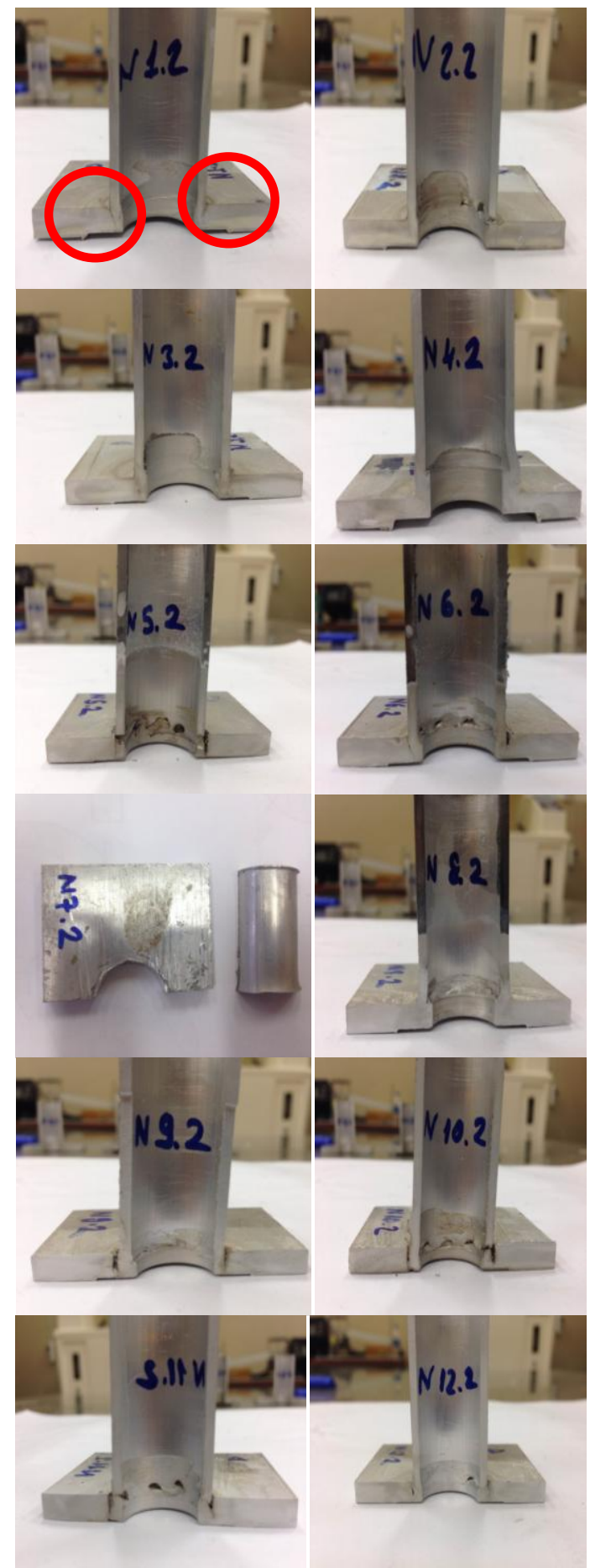

Şekil 5. DTYSK bağlantıların görünümleri 


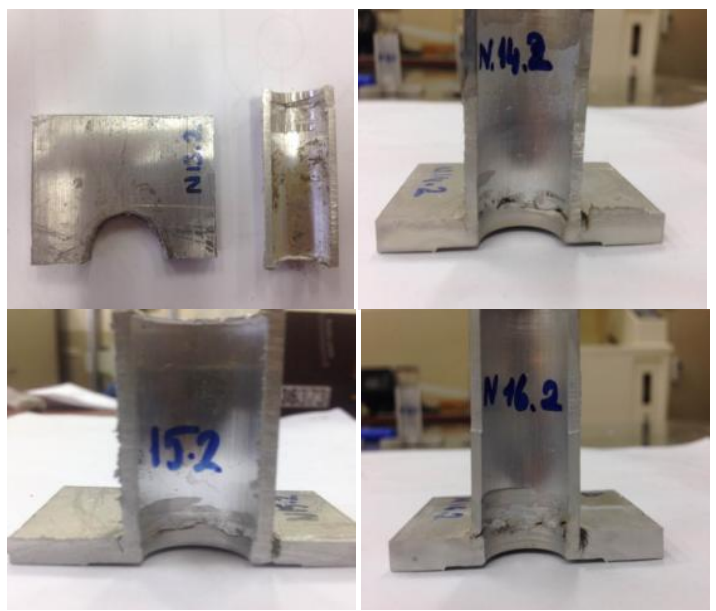

Şekil 5. DTYSK bağlantıların görünümleri (devamı)

Kesme dayanımları ve makroskobik açıdan değerlendirildiğinde en iyi kaynaklı birleştirme N1, N3, N4 kodlu kaynak parametrelerinde elde edilmiştir. Borunun çapı ile takımın pin arasındaki boşluk ne kadar yakın olursa o kadar daha iyi sonuçlar vermektedir.

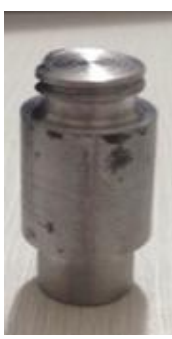

Kesme pimi

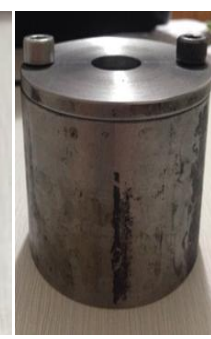

Aparat

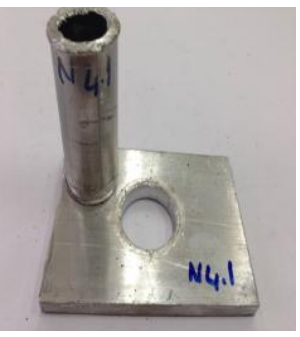

Deney sonrasi ayrılmış boru - plaka
Şekil 6. DTYSK bağlantıların kesme deneyinde kullanılan aparat ve deney sonrası

Literatürde alüminyum ve alaşımlarının kesme dayanımlarına bakıldığında 6063-T5 için 56-90 $\mathrm{MPa}$ arasında değerlerle karşılaşılmaktadır [8-9]. Yapılan deneysel çalışmalarda $53 \mathrm{MPa}$ kesme dayanımına sahip boru plaka bağlantıları tespit edilmiştir. Buradan sonuçların tatmin edici olduğu söylenebilir. Borunun çapı ile takımın pin arasındaki boşluk ne kadar yakın olursa o kadar daha iyi sonuçlar vermektedir. Metalografik içyapı incelendiğinde gerek kaynak bölgesinde gerekse dışında daha önce oluşmuş olan katı çökeltilerin varlığını sürdürdüğ̈̈ görülmektedir (Şekil 7). Yani kaynak esnasında ulaşılan sıcaklıklar bu katı çökeltilerin bozulmasına neden olmamıştır.

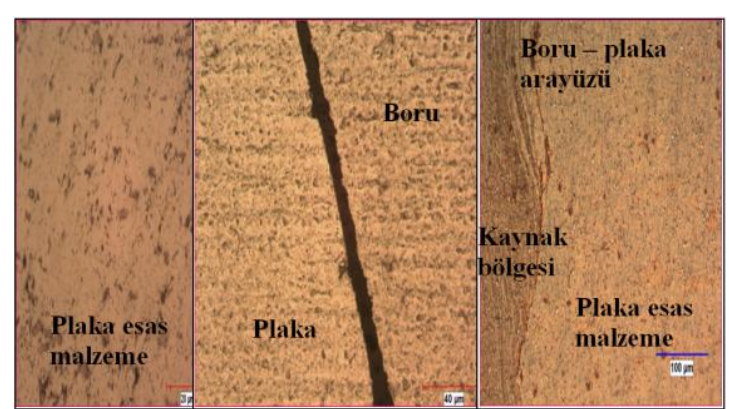

Şekil 7. DTYSK boru-plaka bağlantıların iç yapı görünümleri

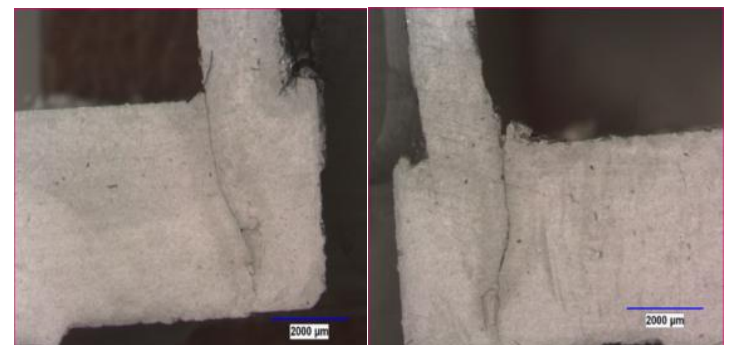

Şekil 8. DTYSK yapılmış boru-plaka ara yüzeyinde birleşme eksikliği

$\mathrm{Bu}$ durumda bazı kaynaklı bağlantıların mukavemetinin istenilenden düşük çıkmasının sebebi yeterli birleştirme sağlanamaması olarak açıklanabilir. Düşük dayanımlı boru-plaka birleştirme ara yüzeyine dikkatli bakıldı ğında dayanımın düşmesine neden olan nüfuziyet eksikliklerinin, çatlakların olduğu, boru-plaka üst birleşim yerinin perçinlemeye benzer kapandığ 1 görülmektedir (Şekil 8). Ancak bu bağlantılar dahi çok yüksek dayanım gerektirmeyen, sızdırmazlık gereken yerlerde yeterli gelebilir.

\section{TARTIŞMALAR}

Boruların plakalara dışarıdan bir takım yardımıyla sürtünme kaynağı üzerine yapılan bu çalışma yöntem olarak ülkemizde uygulanan ikinci çalışma olma özelliği taşımaktadır. Çalışmalarda bazı geliştirilmesi gereken noktaların bulunduğu görülmüştür. Özellikle çalışmalar esnasında 
uygulanan dikey yükü sabit tutan bir sistem, gerçekleştirilecek birleştirmelerin daha istikrarlı ve tekrar edilebilir olmasını sağlayacaktır. Ayrıca birleştirme esnasında erişilen sıcaklık mertebesinin farklı noktalardan daha hassas olarak ölçülmesi malzemelerde ortaya çıkacak olan yaşlanma etkisinin yorumlanmasını kolaylaştıracaktır.

Deneylerde literatürde yapılan bir çalışmaya dayanılarak [14] borular üzerine $3 \mathrm{~mm}$ çapında 8 adet delik açılmış ve ön deneyler yapılmıştır. Delik açılan borularda tatmin edici sonuçlar alındığından çalışmalara bu şekilde devam edilmiştir. Aynı çalışma üzerine delik açılmadan da tekrarlanabilir. Bununla beraber yapılan çalışmalarda dışarıdan bir takım yardımıyla boruların plakalara sürtünme kaynağı ile birleştirilebileceği görülmüştür. Elde edilen dayanım sonuçları da memnun edici sınırlar içindedir. Kaynak işleminin kolay uygulanabilir olması sebebiyle alüminyum ve alaşımları ile başlayan çalışmaların hızla çeliklere doğru yönlendirilmesi özellikle kazan, eşanjör vb. ürünler imal eden firmalar açısından önem teşkil edecektir.

Bununla birlikte farklı baskı kuvvetlerinde, takım omuz çap1 ve profilinin etkileri de yine çalışılabilecek parametreler arasında düşünülmektedir. Elbette ki çalışılabilecek diğer bir parametre ise bu yöntemin diğer malzemelere uygulanabilirliğidir.

Sonuç itibariyle yapılan çalışma göstermiştir ki boruların plakalara dışarıdan bir takımla birleştirilebilirliği üzerine kullanılan borunun plaka yüzeyinden taşma miktarı, boru dış çapı ile levha deliği arasında kalan boşluk kaynaklı bağlantı mukavemetini etkileyen önemli bir parametredir.

\section{TEŞEKKÜR}

Yazarlar metalografik iç yapı inceleme esnasındaki yardımlarından dolayı Pamukkale Üniversitesi Teknoloji Fakültesi Biyomedikal Mühendisliği Bölümünden Araş.Gör. Ali Tekin Güner'e teşekkür ederler.

\section{KAYNAKLAR}

1. Çam, G., 2002. Sürtünme Karıştırma Kaynağ 1 Uygulamalar1, 9. Malzeme Sempozyumu Bildiriler Kitab1, 8-10 May1s 2002, Pamukkale Üniversitesi, 450-458, Denizli.

2. Çam, G., 2003. Sürtünme Karıştırma Kaynağında Kullanılan Takımlardaki Geliştirmeler, TMMOB Makine Mühendisleri Odas1, Kaynak Teknolojisi IV. Ulusal Kongre ve Sergisi, 47-62, Kocaeli.

3. Şık, A. ve Kayabaş, Ö., 2003. Sürtünme Karıştırma Kaynağı ile Yapılan Alüminyumun Kaynağında Kaynak Bölgesinin Mekanik Özelliklerinin İncelenmesi, Gazi Üniv. Endüstriyel Sanatlar Eğitim Fak. Der., 11, 3043.

4. http://bilginform.com/surtunme-karistirmakaynagi.html

5. Mishra, R. S. and Ma, Z. Y., 2005. Friction Stir Welding and Processing, Materials Science and Engineering R 50, 1-78.

6. Kang C.Y., North T.H., Perovic D.D., 1996. Microstructual Features Of Friction Welded MA 956 Superalloy Material" Metall. And Mater. Trans. A, V26A, 4019-4029.

7. Yüksel, M., Meran, C., 2013. Malzeme Bilgisine Giriş, Malzeme Bilimleri Serisi -Cilt 2, MMO yayını, yayın No: MMO/545/2, Ankara, 568.

8. Can, A.Ç., 2015. Makine Elemanları, Boy Yayınları, sy12, Denizli.

9. Yelbey, İ., 2002. Yelbey B., Kalıp Konstrüksiyonu ve Kalıp yapımı, 11.

10. Meran, C., Korkmaz, E., Küçükömeroğlu T., Aksoy, A., Kestel, M., Akder, İ., 2015. Boruların Plakalara Dışarıdan Bir Takımla Sürtünme Kaynak Edilebilirliğinin İncelenmesi, IX. Ulusal Kaynak Teknolojileri Kongre ve Sergisi, Ankara, 471-480.

11. Muthukumaran, S., Athul, P., Venukumar, S., 2013. Friction Welding of $\mathrm{Cu}$-Tube To AlTube Plate Using An External Tool By Threaded Tube Interference Method, Proceedings of the 1st International Joint Symposium on Joining and Welding, 129-135.

12. Senthil Kumaran, S., Muthukumaran, S. Vinodh, S., 2011. Optimization of friction 
welding of tube to tube plate using an external tool by hybrid approach, Journal of Alloys and Compounds 509, 2758-2769.

13. Senthil Kumaran, S., Muthukumaran, S., Vinodh. S., 2010. Optimization of friction welding of tube to tube plate using an external tool, Struct Multidisc Optim, 42:449-457.

14. Senthil Kumaran, S., Muthukumaran, S., Vinodh, S., 2011. Optimization of friction welding of tube-to-tube plate using an external tool by Taguchi method and genetic algorithm, Int J Adv Manuf Technol, 57:167-182.

15. Muthukumaran, S., Senthil Kumaran, S., Saket Kumar, S., 2011. Friction welding of Cu-tube to Al-tube plate using an external tool, Trans. IIM Vol. 64, Issue 3, 255-260.

16. Senthil Kumaran, S., Muthukumaran, S., and Chandrasekhar Reddy, C., 2013. Effect of Tube Preparations on Joint Strength in Friction Welding of Tube-to-Tube Plate Using an External Tool Process, Experimental Techniques 37,24-32.

17. Senthil Kumaran, S., Muthukumaran, S., and Chandrasekhar Reddy, C., 2013. Suitability of Friction Welding of Tube to Tube Plate Using an External Tool Process for Different Tube Diameters-A Study, Experimental Techniques 37, 8-14.

18. Kumar, C.V., Muthukumaran, S., Pradeep, A., Kumaran, S.S., 2011. Optimizational study of friction welding of steel tube to aluminum tube plate using an external tool process, International Journal of Mechanical and Materials Engineering (IJMME), Vol.6, No.2, 300-306.

19. Balaji, G.K., Muthukumaran, S., Senthilkumaran, S., Pradeep, A., 2012. Optimization of Friction Welding of Tube-toTube Plate Using an External Tool with Filler Plate, Journal of materials engineering and performance 21 (7), 1199-1204.

20. Senthil Kumaran S., Muthukumaran, S., 2014. Effect of projection on joint properties of friction welding of tube-to-tube plate using an external tool, Int J Adv Manuf Technol, 75:1723-1733.

21. Senthil Kumarana, S., Muthukumarana, S., Venkateswarlua, D., Balajia, G.K. and Vinodhb, S., 2012. Eco-friendly aspects associated with friction welding of tube-to-tube plate using an external tool process, International Journal of Sustainable Engineering, Vol. 5, No. 2, 120-127.

22. Senthil Kumaran, S., Muthukumaran, S., Vinodh, S., 2010. Taguchi method and genetic algorithm based optimization of FWTPET process parameters, International Conference on Frontiers in Mechanical Engineering (FIME), v60.

23. Muthukumaran, S., Kumar, C.V., Kumaran, S.S., Pradeep, A., 2012. Interfacial Microstructure and Strength of Friction Welding of Steel Tube to Aluminium Tube Plate using an External Tool, Advanced Materials Research 383, 877-881.

24. Senthil Kumaran, S., Muthukumaran, S., 2014. Effect of projection on joint properties of friction welding of tube-to-tube plate using an external tool, The International Journal of Advanced Manufacturing Technology, Volume 75, Issue 9, pp 1723-1733.

25. Muthukumaran, S., Pradeep, C., Vijaya Kumar, C., Senthil Kumaran, S., 2010. Mechanical and metallurgical properties of aluminium 6061 alloy tube to tube plate welded joints welded by friction welding using an external tool process, International Welding Symposium, 235-239.

26. Aykanat, E., Değirmenci, S., 2016. AA6063 (AlMg0,7Si) Boruların Plakalara Dıştan Bir Takımla Sürtünme Kaynak Edilebilirliğinin İncelenmesi, Lisans Tezi, PAÜ Müh. Fak. Makine Mühendisliği Bölümü, Tez Danışmanı: Prof. Dr. Cemal Meran. 